\title{
Experimental Investigation of Design and Fatigue Analysis of Two Wheeler Lighter Weight Compound Wheel
}

\author{
Nagendra Akula ${ }^{1}$, Dr K Rajagopal ${ }^{2}$ \\ ${ }^{1}$ Professor of Mechanical engineering, Dept. Mechanical Engineering St Peters Engineering College, \\ Hyderabad) \\ ${ }_{2}^{2}$ (Professor of Mechanical Engineering, Dept. Mechanical Engineering, SKD University, Anathapuram)
}

\begin{abstract}
Significance of wheel in the vehicles is self-evident. The vehicle may be towed without the motor however in the meantime even that is additionally impractical without the wheels, the wheels along the tire needs to convey the vehicle burden, give padding impact and adapt to the guiding control. The large wheel spokes are the backings comprising of an outspread individual from a wheel joining the centre point to the edge. The most ordinarily utilized materials for making Wheel spokes are with elements of amazing softness, warm conductivity, erosion resistance, qualities of throwing, low temperature, high damping property, machine preparing and reusing, and so forth. This metal primary point of preference is lessened weight, high precision and outline decisions of the wheel. This metal is helpful for vitality preservation in light of the fact that it is conceivable to re-cycle. Spokes make vehicles look extraordinary yet in the meantime they oblige consideration in upkeep. To perform their capacities best, the spokes must be kept under the perfect measure of strain. The two primary sorts of cruiser edges are strong wheels, in which case the edge and spokes are all give a role as one unit and the other talked wheels, where the bike edges are bound with spokes. These sorts of wheels require strangely high talked strain, following the heap is conveyed by less spokes. On the off chance that a spoke does break, the wheel by and large turns out to be in a flash unreadable additionally the centre point may break. Quickly, for engine cycles. Aluminum amalgam wheels are utilized, right now supplanting by new magnesium composite due its preferable properties over Al-compound. A critical ramification of this paper or the issue expressed here is to "dissect the anxiety and the uprooting appropriation contrasting the outcomes acquired". Moreover, this work develops Proper examination of the wheel assumes an imperative part for the security of the rider. A typical alloy wheel configuration of Suzuki GS150R commercial vehicle is chosen for study.
\end{abstract}

Keywords: Wheel, strain, spokes, sorts, aluminum wheel, composites, edges.

\section{Introduction}

The wheel is a device that enables efficient movement of an object across a surface where there is a force pressing the object to the surface. Early wheels were simple wooden disks with a hole for the axle. Because of the structure of wood a horizontal slice of a trunk is not suitable, as it does not have the structural strength to support weight without collapsing; rounded pieces of longitudinal boards are required. The spoke wheel was invented more recently, and allowed the construction of lighter and swifter vehicles. Alloy wheels are automobile wheels which are made from an alloy of aluminium or magnesium metals (or sometimes a mixture of both). Alloy wheels differ from normal steel wheels because of their lighter weight, which improves the steering and the speed of the vehicle, however some alloy wheels are heavier than the equivalent size steel wheel. Alloy wheels are also better heat conductors than steel wheels, improving heat dissipation from the brakes, which reduces the chance of brake failure in more demanding driving conditions. Lighter wheels can improve handling by reducing unstrung mass, allowing suspension to follow the terrain more closely and thus improve grip, however not all alloy wheels are lighter than their steel equivalents. Reduction in overall vehicle mass can also help to reduce fuel consumption.

\section{The Problem with Mag Wheels in Early Days}

1. Magnesium alloy wheels, or mag wheels, are sometimes used on race cars, in place of heavier steel or Aluminium wheels, which are heavier than MAG wheels most street vehicles. Note that aluminium wheels are often mistakenly called "mag wheels". Oil consumption reduction and performance enhancement have become the development trend of road vehicles, especially for motorcycles. Due to the nature of high-speed motion and rotation, weight reduction of the wheels is thought of as the most efficient way to reduce the oil consumption, improve the accelerating and braking performance, and enhance the riding comfort of a road vehicle. Naturally, use of lightweight materials on the wheels is the most straightforward way to achieve the goal. So recent developed Magnesium alloys are considered as the most promising metal material in the 21st 
century, which possesses the attractive properties desired by motorcycles in comparison with steel and $\mathrm{Al}$ alloy, such as low density, low cost, higher specific strength, good casting properties, and outstanding damping capability. When used as wheel material, Mg alloys are not only able to reduce the wheel mass and save oil, but also facilitate absorbing vibration and damping the noise emission, enhancing accelerating and braking performance, thus improving the resultant riding comfort. From steel wheel to $\mathrm{Al}$ wheel, lightweight $\mathrm{Mg}$ alloys have become the first candidate material of wheels.

\subsection{WHY MAG WHEELS ONLY?}

Magnesium is best known for its light weight but it also has some other excellent attributes. Magnesium alloys have excellent strength to weight ratio, good fatigue strength and high damping capacity. Its nonmagnetic, has good thermal and electrical conductivity. Magnesium can be shaped by practically all the known metal working techniques like cast by the sand, investment, permanent mould and die casting, extruded, processed via powder metallurgy technology, can be formed into shapes by forging, drawing, spinning, stamping, impact extrusion and super plastic forming. To further enhance safety, a new generation of wrought and sand casting magnesium alloys has been developed, Electron 43, 21, and 675, ZK 60 etc. which are inherently flame - resistant even beyond their melting points.

\subsection{MG ALLOYS ARE WELL KNOWN FOR THE FOLLOWING PROPERTIES}

1. Ultra-lightness 2. Strength 3. Machinability 4. Castability 5. EMI/ RF Radiation shielding 6. Low inertia

7. Creep Resistance 8. Formability 9. Dent Resistance 10. Corrosion Resistance

\section{Objective}

To create simulations of various alloy wheel designs that focus on reducing the mass of the current design and selecting better material. The new designs include reducing the number of spokes, modifying the fillet radius at the intersection of the spoke and the hub.

\subsection{DESIGNI OF ALUMINIUM TO MAGNESIUM}

Magnesium is best known for its light weight but it also has some other excellent attributes. Magnesium alloys have excellent strength to weight ratio, good fatigue strength and high damping capacity. Its nonmagnetic, has good thermal and electrical conductivity. Magnesium can be shaped by practically all the known metal working techniques like cast by the sand, investment, permanent mould and die casting, extruded, processed via powder metallurgy technology, can be formed into shapes by forging, drawing, spinning, stamping, impact extrusion and super plastic forming. To further enhance safety, a new generation of wrought and sand casting magnesium alloys has been developed, Electron 43, 21, and 675, ZK 60 etc. which are inherently flame - resistant even beyond their melting points.

\subsection{EFFECTS OF ALLOYING ADDITIONS}
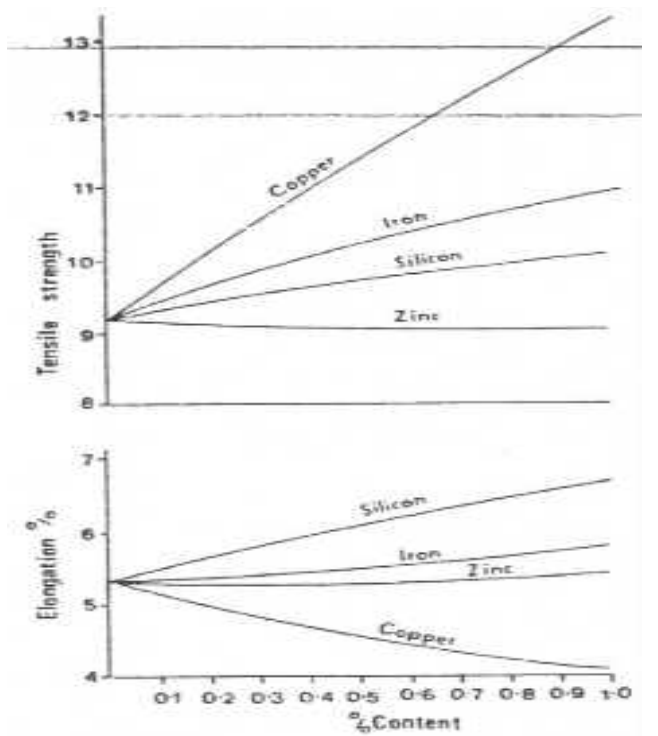

Fig.1 Effects of alloying additions on tensile strength and ductility 


\subsection{GEOMETRIC PROPERTIES OF ALLOY WHEEL}

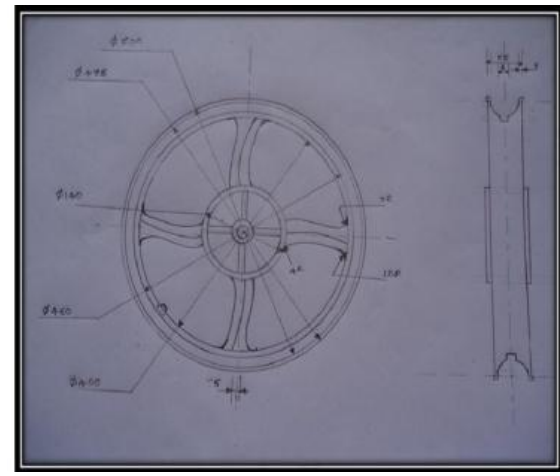

\begin{tabular}{|c|c|c|c|}
\hline Hub Diameter & $145 \mathrm{~mm}$ & Rim thickness & $6 \mathrm{~mm}$ \\
\hline Hub thickness & $8 \mathrm{~mm}$ & Rim outer diameter & $500 \mathrm{~mm}$ \\
\hline Spoke Length & $155 \mathrm{~mm}$ & Number of spokes & 6 to 4 \\
\hline Spoke fillet radii & \multicolumn{3}{|c|}{$\begin{array}{c}\text { at hub 4R } \\
\text { at outer rim 8R \& 13R }\end{array}$} \\
\hline
\end{tabular}

Fig. 2 drawing of new model alloy wheel

\subsection{CORROSION RESISTANCE}

Forged mag wheels are extremely durable and rigid. The strength of a forged wheel made from magnesium alloy exceeds many times the strength of a cast $\mathrm{Al}$ disk. This is achieved by forming a unique fibre structure of the alloy manufactured by the precision 3-D hot forging process in a press with a 20,000 ton capacity. A forged wheel does not crack; it bends without cracking and can be easily repaired, if necessary. Common casting defects, such as cavities and cracks, are non-existent in forging.

MODELING OF ALLOY WHEEL USING SOLIDWORKS SOLIDWORKS is software which is used for creation and modifications of the objects. In SOLIDWORKS and design and modelling feature is available. Design means the process of creating a new object or modifying the existing one. Drafting means the representation or idea of the object. Modelling means create and converting 2D to 3D. By using SOLIDWORKS software, create the model of the wheel rim.

\subsection{SPOKES OF THE ALLOY WHEEL}

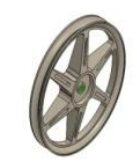

Fig 3 Model name: 6-spoke

\subsection{ANALYSIS}

Designers and engineers primarily use structural simulation to determine the strength and stiffness of a product by reporting component stress and deformations. The type of structural analysis performs depends on the product being tested, the nature of the loads.

\subsection{MESHING}

Meshing involves division of the entire of model into small pieces called elements. This is done by meshing

\subsection{MESH INFORMATION AND DETAILS ARE REPRESENTED AS IN TABLE}

\begin{tabular}{|c|c|c|c|}
\hline Mesh type & \multicolumn{3}{|c|}{ Solid Mesh } \\
\hline Mesher Used: & \multicolumn{3}{|c|}{ 4 Points } \\
\hline Jacobian points & \multicolumn{3}{|c|}{ mesh } \\
\hline TYPE OF WHEEL MODEL & With 6 Spokes & With 5 Spokes & With 4 Spokes \\
\hline Element Size & $6 \mathrm{~mm}$ & $6 \mathrm{~mm}$ & $6 \mathrm{~mm}$ \\
\hline Tolerance & $0.3 \mathrm{~mm}$ & $0.3 \mathrm{~mm}$ & $0.3 \mathrm{~mm}$ \\
\hline Mesh Quality & High & High & High \\
\hline Total Nodes & 138283 & 129933 & 121024 \\
\hline Total Elements & 77485 & 72121 & 66289 \\
\hline Maximum Aspect Ratio & 27.471 & 27.339 & 27.337 \\
\hline \% of elements with Aspect Ratio <3 & 76.2 & 74.2 & 72.8 \\
\hline \% of elements with Aspect Ratio > 10 & 0.246 & 0.326 & 0.291 \\
\hline \% of distorted elements(Jacobian) & 0 & 0 & 0 \\
\hline Time to complete mesh*(hh;mm;ss): & $00: 02: 00$ & $00: 01: 59$ & $00: 01: 56$ \\
\hline
\end{tabular}

International Conference on Recent Innovations in Civil \& Mechanical Engineering

[i-CAM2K16] DOI: 10.9790/1684-16053026066

$62 \mid$ Page 


\subsection{MESHED MODEL OF THE RIM WHEEL WITH DIFFERENT SPOKES:}

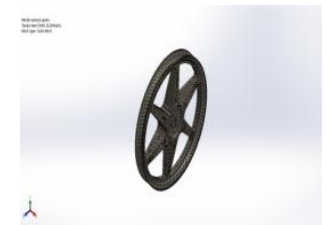

Fig.4 Model name: 6-spoke

\subsection{APPLIED LOADS}

Load for 6 spokes $=(163+65 X 6) \mathrm{kg}$

2.11 ANALYSIS FOR STRENGTH NEED:

Mass of Bike, Dead Weight of Bike $=143 \mathrm{~kg}$

Other Loads $\quad=20 \mathrm{Kg}$

Total Gross Weight $\quad=143+20=163 \mathrm{Kg}$

$$
=163 \mathrm{X} 9.81 \mathrm{~N}
$$

Tires and Suspension system reduced by $30 \%$ of Loads

$\mathrm{W}_{\text {net }}=163$ X 9.81 X $0.7 \mathrm{~N}=1119.32 \mathrm{~N}$

Reaction Forces On Bike $=\mathrm{N}_{\mathrm{r}}=1119.32 \mathrm{~N}$ Number of Wheels: 2

But by considering total Reaction Force on only one wheel FT $=1119.32 \mathrm{~N}$

Rim surface area which is having 6 spokes: A6 $=48299.69 \mathrm{~mm} 2$ (this can be obtained from selecting faces on rim by using measuring tool in solid works)

Stress on the each $\operatorname{Rim}=\mathrm{N} / \mathrm{A}=0.02321 \mathrm{~N} / \mathrm{mm} 2$

So pressure on the each rim for load $0=0.02321 \mathrm{~N} / \mathrm{mm} 2$

It is similarly for different Loads Stress on Each Rim with Load

Pressure by Load by 6 spokes $\quad=0.0786 \mathrm{~N} / \mathrm{mm} 2$

\section{Applying Pressures}

Apply 0.011945MPa pressure simulations normal to the faces as shown in the figure

Again it is similarly for rims with spokes $5 \& 4$. The simulation results are as shown in figures.

\subsection{APPLYING BRAKING TORQUE}

In general Acceleration of the street motorcycle: $\mathrm{a}=(\mathrm{vf}-\mathrm{vi}) / \mathrm{t}$ vf- final velocity $=$ max of $60 \mathrm{miles}$ in $3.5 \mathrm{sec}$ vi- initial velocity $=0$ miles,

$=>\mathrm{a}-$ acceleration $=7.6636 \mathrm{~m} / \mathrm{s} 2$

Brake force is required to estimate the load on the wheel hub. Now Total force acting on the vehicle:

Mass of the vehicle including rider and other five more persons $M=163+65 \mathrm{X} 6$

$\mathrm{F}_{\text {total }}=\mathrm{M} \mathrm{X} \mathrm{a}=4237.9 \mathrm{~N}$

\subsection{TORQUE ON THE HUB}

$\mathrm{T}=\mathrm{Fr} \mathrm{X} \mathrm{R}$ in N.m (here Fr is the force on the each wheel $=0.5 \mathrm{Ftotal} \&$ is $\mathrm{R}$ radius of the rim $=0.25 \mathrm{~m}$ ) $\mathrm{T}=$ $2119 \times 0.25=529$ N.m

Table Max. Von Mises Stress due to braking torque in the wheel (by considering drum braking):

\begin{tabular}{|c|c|}
\hline in 6 spoke Al-alloy wheel & $251.526>$ yield stress \\
\hline
\end{tabular}

\subsection{MESH INFORMATION}

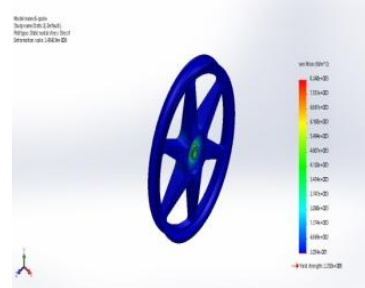

\begin{tabular}{|l|l|l|l|}
\hline Name & Type & Min & Max \\
\hline Stress1 & VON: & $1.374 \mathrm{e}+003$ & $7.553 \mathrm{e}+003$ \\
& von & $\mathrm{N} / \mathrm{m}^{\wedge} 2$ & $\mathrm{~N} / \mathrm{m}^{\wedge} 2$ \\
& Mises & Node: 22872 & Node: 22059 \\
& Stress & & \\
\hline
\end{tabular}

Fig.5 6 Spoke Static Stress 
Experimental Investigation of Design and Fatigue Analysis of Two Wheeler Lighter Weight ..

\subsection{FATIGUE ANALYSIS}

\begin{tabular}{|l|l|}
\hline Study name & Fatigue 1 \\
\hline Analysis type & Fatigue(Constant Amplitude) \\
\hline Event Interaction & Multi Interactions \\
\hline Computing alternating stress using & Equivalent stress (von Mises) \\
\hline Shell face & Top Face \\
\hline Mean stress correction & None \\
\hline Fatigue strength reduction factor & 0.9 \\
\hline Infinite life & Off \\
\hline
\end{tabular}

Fatigue analysis of Spoke wheels of Al Alloy

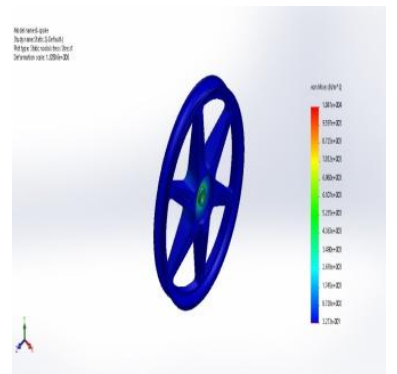

\begin{tabular}{|l|l|l|l|}
\hline Name & Type & Min & Max \\
\hline Stress1 & VON: von & 5842.41 & $2.01831 \mathrm{e}+007$ \\
& Mises Stress & N/m^2 & N/m^2 \\
& & Node: & Node: 22059 \\
& & 22872 & \\
& & & \\
& &
\end{tabular}

Fig6- 6Spoke Static Stress

\subsection{S-N DATA}

S-N Data Plot

S-N Data Plot

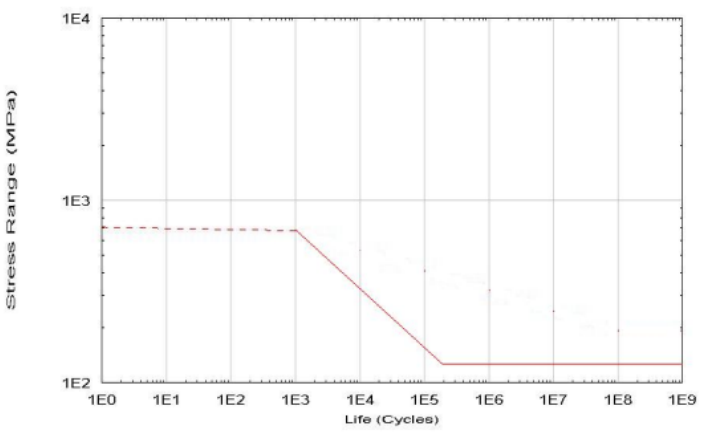

Fig.7 S-N Data Plot of Aluminum alloy

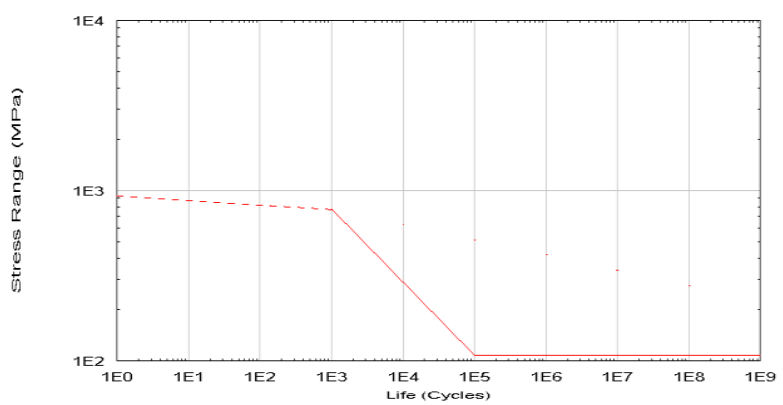

Fig.8 S-N Data Plot of Magnesium Alloy

IV. Results

Table: 1 Weight $(\mathrm{N})$ reductions in the model

\begin{tabular}{|c|c|c|c|}
\hline No. of spokes & $\mathbf{M g}$ & Al & \% of weight saving \\
\hline 6 spokes & 24.3911 & 40.1294 & 60.78 \\
\hline 4 spokes & 19.1728 & 31.608 & 60.66 \\
\hline
\end{tabular}

From the above table of weight reduction $\mathrm{n}$ the model in the 4spoke model design of the Mg alloy saved the much amount of the weight reduction of $60.66 \%$

Table: 2 Max. Von Mises Stress due to braking torque in the wheel

\begin{tabular}{|c|c|}
\hline in 4 spoke Al-alloy wheel & $250.148>$ yield stress \\
\hline in 4 spoke Mg-alloy wheel & $\begin{array}{c}246.472<\text { yield stress } \\
\text { (safe stresses) }\end{array}$ \\
\hline
\end{tabular}

In both of the 4 spoke alloy wheels; stresses induced on the wheel to the maximum Von mises stresses are safe in $\mathrm{Mg}$ alloy than $\mathrm{Al}$ alloy 
Experimental Investigation of Design and Fatigue Analysis of Two Wheeler Lighter Weight ..

Table:3 Comparative Static Analysis of Alloy Wheels for Different Materials

\begin{tabular}{|c|c|c|c|c|c|c|}
\hline \multicolumn{9}{|c|}{ Static Analysis } \\
\hline & \multicolumn{2}{|c|}{ Stress (N/mm2) } & \multicolumn{2}{c|}{ Displacement (mm) } & \multicolumn{2}{c|}{ Strain } \\
\hline & MIN & MAX & MIN & MAX & MIN & MAX \\
\hline Aluminium & 0.00165150 & 2.11428 & 0 & 0.00382573 & $61658 \mathrm{e}-008$ & $53612 \mathrm{e}-005$ \\
\hline Magnesium & 0.00139368 & 2.10330 & 0 & 0.00617055 & $96084 \mathrm{e}-008$ & $26829 \mathrm{e}-005$ \\
\hline
\end{tabular}

The Stresses induced in the 4-Spokes Mg Alloy wheel are less as compared with the Stresses with the Al alloy.

Table: 4 Fatigue Analyses of Alloy Wheels for Different Materials

\begin{tabular}{|c|c|c|c|c|c|c|}
\hline \multicolumn{7}{|c|}{ Fatigue Analysis } \\
\hline & \multicolumn{2}{|c|}{ Total Life (Cycles) } & \multicolumn{2}{|c|}{ Damage Factor } & \multicolumn{2}{|c|}{ Load Factor } \\
\hline & MIN & MAX & MIN & MAX & MIN & MAX \\
\hline Aluminum & $1 e+006$ & $1 e+006$ & 10 & 10 & 92.7230 & 115533 \\
\hline Magnesium & $1 e+006$ & $1 e+006$ & 10 & 10 & 57.8465 & 80884.7 \\
\hline
\end{tabular}

The fatigue analysis results clearly show that $\mathrm{Mg}$ Alloy material is sustained for $1 \mathrm{e} 20$ cycles. Maximum damage occurred till the end of the $1 \mathrm{e} 20$ cycles is $0.2 \%$.

\section{Conclusion}

In the optimization of wheel rim, the wheel structure and its features are divided into two parts, namely design space and non design space. The non design space is the standard design and cannot be modified. The design space is the region for optimizing the weight and shape of the arms. The wheel design space is optimized in order to withstand the existing load of the vehicle with the factor of safety with a least quantity of material and manufacturing cost and losses.

Following are the conclusions from the results obtained:

1. The maximum stress area was located at Spoke-Rim contact.

2. Stresses induced in 4-Spokes Alloy wheel are less as compared with Al-Alloy of the 5and 6 Spokes.

3. The weights of the Mg alloy with 4-Spokes wheel is less as compared with Al-Alloy of the 6,5and 4 Spokes.

4. The fatigue analysis results clearly show that $\mathrm{Mg}$ Alloy material is sustained for $1 \mathrm{e} 20$ cycles. Maximum damage occurred till the end of the $1 \mathrm{e} 20$ cycles is $0.2 \%$.

5. Fatigue life cycle for the Mg-alloy is more as compared with all Al-alloys materials.

6. Induced Stress due to braking torque in the $4 \mathrm{Mg}$-Spoke wheel are lesser than the remaining wheels.

7. Material reduction can be done by reducing number of Spokes. The objective was to reduce the weight of the alloy wheel has been achieved. The current design is $60 \%$ lighter than the original design. The objective was to reduce the weight of the alloy wheel has been achieved. The current design is $60 \%$ lighter than the original design.

8. In this work the overall dimensions are controlled by reducing number of spokes to the alloy wheel with same functioning stability and less weight. The stress and displacements in 4 spoke alloy wheel are lesser than six and five spokes alloy wheels.

\section{References}

[1]. Coaxial, Z. (2006). - Design and structural analysis of aluminium alloy wheel, PhD Dissertation, Zhejiang University, Zhejiang.

[2]. Angmo Wang - Yufa Chen - Chenzhi Wang - Qingzheng Wang (2009),Fatigue Life Analysis of Aluminium Wheels by Simulation of Rotary Fatigue Test thesis in School of Mech Engineering, Nanjing University of Science \& Technology, China.

[3]. RamamurtyRaju, P., Satyanarayana, B., Ramji, K., Suresh Badu, K. (2007), -Evaluation of fatigue life of aluminium alloy wheels under radial loads, Journal Engineering Failure Analysis.

[4]. Wei-Chan Chang (2008), - Modelling for Impact Test of Aluminium Wheels, Department of Mechanical Engineering National Central University Jhong-Li 32001, Taiwan, R.O.C

[5]. M.Riesner and R. I. DeVries, -Finite Element Analysis and Structural Optimization of Vehicle Wheels, in Proceedings of International Congress \& Exposition - SAE, Detroit, MI, 1993.

[6]. Chan, - Analysis of Impact Test for Aluminium Alloy Wheel,॥(2006) National Yunlin University of Science \& Technology

[7]. N.Satyanarayana \& Ch.Sambaiah (2012), -Fatigue Analysis of Aluminium Alloy Wheel Under Radial Load, (IJMIE), ISSN No.2231 -6477, Vol-2, Issue-1, 2012

[8]. WU Li-hong1, LONG Si-yuan2, GUAN Shao-kang1 (2009),-Verification of Applying Mg-Alloy AM60B to Motorcycle Wheels with FEM, College of Materials Science and Engineering, Chongqing University, China. 
[9]. Wu Lihong, Long Siyuan, Guan Shaokang. - Study on structural optimum technology of motorcycle Mg-alloy wheel Machinery Design \& Manufacture, 2006, (9):85-87

[10]. Wu Lihong, Long Siyuan, Xu Shao-yong, et al. - Influences of Mg alloy and Al alloy on service stress in motorcycle wheel. Materials Science and Technology, 2007, 15(3): 397-100.

[11]. Cleginaldo Pereira de Carvalho (2002), - Wheels - An Approach for Structural Analysis and Fatigue Life Prediction, Journal of Mechanical Engineering

[12]. Msc. Shaymaa Mahmood (2011), Engineering Materials. National Instruments (2009), Static and Fatigue Structural Test Tutorial.

[13]. MOHD ZUL HAZMl BIN MHD FAUZY (2008), -Finite Element Analysis of Car Alloy Wheel, thesis in UNIVERSITI TEKNIKAL MALAYSIA MELAKA.

[14]. Lawrence and Miller, P., "Wheel materials," SAE technical publication \#880697, 1988.

[15]. The Automotive Research Association of India (2007), -Automotive Vehicles Wheel Rims for Two and Three Wheeled Vehicles - Light Alloy Wheel Rims - Method of Test and Requirements Ministry of Shipping, Road Transport \&highways Government of India.

[16]. Wei, D., "Rim section fatigue results of Aluminium and Steel wheels, SAE Report 01612, 1992.

[17]. Wright, D, "Test Methods for Automotive Wheels," I Mech E Conference Publications.

[18]. S Vikranth Deepak, C Naresh and Syed AltafHussain (2012), - Modelling and Analysis of Alloy Wheel for Four Wheeler Vehicle, ISSN 2278-0149

[19]. D.Apelian (2009), - Aluminium cast Alloys; For Enabling Tool and Improved Performance, North American Die Casting Association, Wheeling.

[20]. Hongyu Wang, "Geometric Parameters Optimal Design of Variable Cross-Section Rim", SAE-China and FISITA (eds.), PP. 1003-1008 